\title{
Examining the Accumulated Oxygen Deficit Method in Front Crawl Swimming
}

Authors

Affiliations
V. M. Reis ${ }^{1,2}$, D. A. Marinho' ${ }^{2,3}$, F. B. Policarpo ${ }^{2}$, A. L. Carneiro ${ }^{2}$, C. Baldari ${ }^{4}$, A. J. Silva $a^{1,2}$

Affiliation addresses are listed at the end of the article
Key words

oxygen uptake

- swimming velocity

- regression error

$\checkmark$ anaerobic energy accepted after revision January 19, 2010

\section{Bibliography}

DOI http://dx.doi.org/

10.1055/s-0030-1248286

Published online:

March 18, 2010

Int J Sports Med 2010; 31:

421-427 () Georg Thieme

Verlag KG Stuttgart · New York

ISSN 0172-4622

\section{Correspondence}

\section{Prof. Victor Machado Reis}

UTAD Sports Apartado 1013 5000 Vila Real

Portugal

Tel.: + 351/259/350877

Fax: $+351 / 259 / 330168$

vreis@utad.pt

\section{Abstract}

$\nabla$

The present study investigated the Accumulated Oxygen Deficit (AOD) method in front crawl swimming with the aims to assess the robustness of the oxygen uptake/swimming velocity regression line and to quantify the precision of the AOD. Twenty-nine male swimmers performed two swimming tests in different days, with a $24 \mathrm{~h}$ recovery between tests: a graded test and an allout test. The all-out test was performed either in $100 m(n=11), 200 m(n=13)$ or $400 m(n=5)$. Through all testing expired gases were collected breath by breath and analysed with a K4b2 Gas Analyser (Cosmed, Rome, Italy) connected to

\section{Introduction}

\section{$\nabla$}

The determination of the energy cost of swimming (Cs) has been well reported since the seventies. Initially, researchers assessed the Cs solely by the contribution of aerobic processes, monitoring $\mathrm{VO}_{2}$ at sub maximal or even maximal intensities [7]. The lack of attention given to the anaerobic contribution (ANAER) to overall energy demand can be justified by difficulties imposed in the assessment of anaerobic energy release. Some attempts have been made to overcome this gap, assessing the Cs with the combination of data from aerobic and anaerobic energy pathways.

The most common procedure to assess anaerobic energy release is to use the values resulting from the transformation of net blood lactate concentration into $\mathrm{O}_{2}$ equivalents $[15,18,34]$. This method is based on a number of assumptions which are similar to that underlying other methods that are used to understand human physiology during exercise (i.e. amount of muscle mass involved), although some have suggested that the lactate $\mathrm{O}_{2}$ equivalent may not be a quantitative an AquaTrainer Valve (Cosmed, Rome, Italy). The error of oxygen uptake/swimming velocity regression lines was $\approx 4-5 \mathrm{ml} \cdot \mathrm{kg}^{-1} \cdot \mathrm{min}^{-1}$ ) and the regressions allowed an extrapolation of the energy cost to higher intensities with a standard error of prediction of $\approx 3-4 \mathrm{ml} \cdot \mathrm{kg}^{-1} \cdot \mathrm{min}^{-1}$. However, the data variability was considerable (95\% confidence intervals of the linear extrapolation larger than $13 \mathrm{ml} \cdot \mathrm{kg}^{-1} \cdot \mathrm{min}^{-1}$ ). The AOD imprecision varied among the three distance events from $\approx 3-13 \mathrm{ml} \cdot \mathrm{kg}^{-1}$. These absolute errors are small, considering the time that subjects took to cover the three distances, but relative to the AOD values that were estimated they can be considered high, especially in the $400 \mathrm{~m}$ bout. measure of ANAER [20]. A different approach that can be used to assess ANAER is through the accumulated oxygen deficit (AOD). This method also requires a number of physiological assumptions and an agreement between AOD and energy equivalent from blood lactate measurements was previously reported [19]. The AOD precision may be assessed for each individual and exercise condition, thus providing information on the accuracy of the method. This methodology has been vastly applied in other sports, both in laboratory $[6,29]$ as well as in field testing $[9,26]$.

Few have reported the analysis of the AOD and the subsequent ANAER during Front crawl swimming $[21,22,31-33,35]$, while others have presented estimates on the anaerobic energy release during swimming using different approaches $[15,34]$. Ogita et al. [21] describe a maximum AOD of $\approx 38 \mathrm{ml} \cdot \mathrm{kg}^{-1}$ for supra maximal 2-3 min bouts in the swimming flume. Silva et al. [31] were able to find an ANAER of $15 \%$ to the overall energy release during the $200 \mathrm{~m}$ freestyle event, a lower value than the estimates of Zamparo et al. [34] for the same distance. Thus, little information on the AOD and how this measure may be of 
interest to assess anaerobic energy release during swimming is available.

Medbø et al. [19] were the first to present a detailed study on the precision of the AOD estimation for treadmill running. Others have subsequently assessed the robustness of the method by the precision of the supra maximal energy demand prediction error $[29,30]$ or by the precision of the AOD itself [26]. In cycling exercise, Russell et al. [29] showed that the inclusion of exercise intensities above the lactate threshold in the $\mathrm{VO}_{2}$ /exercise intensity regression line did not significantly change the AOD but did improve the precision of the estimated supra maximal energy demand. In running, Reis et al. [25] reported that the inclusion of exercise intensities above the lactate threshold in the $\mathrm{VO}_{2} /$ intensity regression does not improve the precision of the total energy demand and that of AOD in endurance-trained runners. Nevertheless, a tendency for an underestimation of the AOD and for a larger imprecision was found when exclusively sub threshold intensities were used. Taking into account these results, Reis et al. [25] suggested that the use of complete regressions (including a wide spectrum of exercise intensities) is more suitable to estimate the total energy demand and the AOD of endurancetrained subjects. However, to our knowledge, no study on the precision of the AOD estimation in swimming is available.

The extent to which AOD may relate to swimming performance is still poorly understood. However, it is our opinion that prior to using such estimates when attempting to predict performance it is necessary to understand how precise the AOD estimation is and how much its precision varies among different distance events. Therefore, the present study intended to investigate the AOD method in front crawl swimming.

The aims of the present study were: i) to assess the robustness of the oxygen uptake/swimming velocity regression line in front crawl swimming; ii) to assess the robustness of the linear extrapolation of supra maximal oxygen demand from the oxygen uptake/swimming velocity regression line in front crawl swimming; iii) to quantify the precision of the AOD in supra maximal front crawl swimming.

We hypothesized that the oxygen uptake/swimming velocity regression line could present a precision that enables the calculation of AOD with an error within the literature references for running or cycling $\left(\approx 5 \mathrm{ml} \cdot \mathrm{kg}^{-1}\right)$.

\section{Methods \\ $\nabla$ \\ Participants}

Twenty-nine male swimmers volunteered after medical approval and gave informed consent to participate in the present study. The present study meets the ethical standards of the International Journal of Sports Medicine [13]. All subjects were involved in systematic training and competition programs (from 9-12 weekly training sessions) and participated regularly in swimming front crawl events. A stadiometer with a range scale of $0.10 \mathrm{~cm}$ was used for the evaluation of height and a standard scale weighing machine was used to assess body mass. Skinfolds were taken with a skinfold caliper Slim Guide (Creative Health Products, USA) to estimate fat percentage as suggested by Faulkner protocol [11]. These measurements were performed during the first day of the experimental tests, before the graded test. The mean ( \pm 1 standard deviation) of their age, height, arm span, body mass and estimated fat percentage were $18.2 \pm 2.6$ years, $1.78 \pm 0.06 \mathrm{~m}, 1.86 \pm 0.06 \mathrm{~m}, 68.9 \pm 11.6 \mathrm{~kg}$ and $10.3 \pm 0.8 \%$, respectively. The swimmers' personal best performance at the time of the measurements in the $100 \mathrm{~m}, 200 \mathrm{~m}$ and $400 \mathrm{~m}$ in short length (25m swimming pool) were $54.92 \pm 4.17 \mathrm{~s}$, $127.78 \pm 1686 \mathrm{~s}$ and $261.9 \pm 10.4 \mathrm{~s}$, respectively.

\section{Procedures}

During the five days prior to the experiment the subjects were not engaged in high-intensity training sessions and limited their training program to a single daily low-intensity swimming session. The subjects performed two swimming tests on different days, with a $24 \mathrm{~h}$ recovery between tests: a graded swimming test and an all-out test. Both tests were conducted in a $25 \mathrm{~m}$ swimming pool in the morning (between 10 a.m and 12 a.m.) at a room temperature of 25-28 degrees Celsius and with a humidity of $50-60 \%$.

\section{Graded and intermittent test}

The first test included several exercise bouts. During this test the swimming speed of the subjects was kept constant by an electronic pacer, with successive flashing lights, placed at the bottom of the pool (TAR. 1.1, GBK-electronics, Aveiro, Portugal). The subjects were instructed to follow the pacer light signal. Distance of the two first bouts was $350 \mathrm{~m}$, and $400 \mathrm{~m}$ from the third bout on. Initial velocity was established according to the swimmers' individual performance in the $400 \mathrm{~m}$ freestyle minus 5 increments of velocity. The increments were $10 \%$ of the $400 \mathrm{~m}$ best performance velocity per each $400 \mathrm{~m}$ stage until exhaustion. No warm-up was performed before the start of the test and recovery between successive bouts was individualized. The subjects started each bout when their $\mathrm{VO}_{2}$ presented two consecutive values within $2 \mathrm{ml} \cdot \mathrm{kg}^{-1} \cdot \mathrm{min}^{-1}$ from that recorded before the start of the first bout (average $\mathrm{VO}_{2}$ during the $2^{\text {nd }}$ min prior to the start of the first bout of the graded test). The test was started with the subjects inside the pool (after the signal the subjects pushed-off the wall with their feet and started to swim). Every $25 \mathrm{~m}$ the turn-over was performed with a body rotation to the side of the lateral wall, without diving, subsequent feet pushoff from the wall and reduced gliding. The graded test ended by subject's voluntary exhaustion or until they could no longer swim at the predetermined pace. Immediately after the conclusion of each bout, capillary blood samples were collected from the finger to determine the blood lactate concentration.

\section{All-out test}

The second test consisted of an all-out swimming test. The allout test was performed at one of the three distances: $100 \mathrm{~m}$ $(n=11), 200 m(n=13)$ or $400 m(n=5)$. Subjects were assigned to each distance according to their best competitive performance and were asked to swim as if they were in a timed competition race.

Subjects were allowed to perform their regular competition warm-up procedures. However, the test was not started until the subjects' $\mathrm{VO}_{2}$ returned to resting values (the same individual value recorded for each subject before the start of the graded test). Each subject performed the test individually. The start of the test and each turn-over were performed as described in the graded test. In addition, capillary blood sample collections were made every 2 min post-race until blood lactate (BL) concentration levelled off. 


\section{Data collection}

Through all testing expired gases were collected breath by breath and analysed with a K4b2 Gas Analyser (Cosmed, Rome, Italy) connected to an AquaTrainer Valve (Cosmed, Rome, Italy). $\mathrm{VO}_{2}$ was averaged for $20 \mathrm{~s}$ intervals. Before each test, a reference air calibration of the device was performed using a gas sample with a $16 \% \mathrm{O}_{2}$ concentration and a $5 \% \mathrm{CO}_{2}$ concentration. The flow meter was also calibrated before each testing with a $3000 \mathrm{ml}$ syringe. Whole blood lactate concentration was measured with an Accusport device (Boehringer, Mannheim, Germany). Despite the accuracy previously demonstrated by this equipment [1], before each test a calibration of the Accusport was performed with several YSI 1530 Standard Lactate Solutions (2, 4, 8 and $\left.16 \mathrm{mmol} \cdot \mathrm{L}^{-1}\right)$.

The graded test was performed to obtain $\mathrm{VO}_{2} /$ velocity relation dots that enabled the calculation of a valid linear regression equation. Although it has been suggested that, theoretically, this relationship should include the cube swimming velocity, data available in the literature clearly shows that the former procedure is less accurate when compared with the linear regression procedure [2]. Peak $\mathrm{VO}_{2}$ was the highest 20 s average $\mathrm{VO}_{2}$ value observed in each subject either in the graded or in the all-out tests. Swimming velocity associated with peak $\mathrm{VO}_{2}$ was estimated from the inclusion of the peak $\mathrm{VO}_{2}$ of each subject in the individual $\mathrm{VO}_{2}$ /velocity regression equation. The $\mathrm{VO}_{2} /$ velocity regression was developed for each subject using the steady-state $\mathrm{VO}_{2}$ values during the last min of each exercise bout in the graded test. Bouts that failed to comply with the $\mathrm{VO}_{2}$ steadystate attainment (given by a difference below $2 \mathrm{ml} \cdot \mathrm{kg}^{-1} \cdot \mathrm{min}^{-1}$ between two consecutive minutes) were not included in the regressions. An individual resting $\mathrm{VO}_{2}$ measurement (zero speed $\mathrm{VO}_{2}$ ) was also included in the regressions. Oxygen uptake measurements from incomplete bouts (less than $400 \mathrm{~m}$ ) were not included in the regression.

The Cs was determined from the slope of the $\mathrm{VO}_{2}$ /velocity regression line. Accumulation of blood lactate in the graded test was traced by linear interpolation to determine the swimming velocity corresponding to the $4 \mathrm{mmol} \cdot \mathrm{L}^{-1}$ threshold.

The accumulated oxygen deficit (AOD) was calculated as the difference between total energy demand (ED) and accumulated $\mathrm{VO}_{2}\left(\mathrm{VO}_{2} \mathrm{Ac}\right)$ during the all-out tests. This estimation was not corrected for body oxygen stores. Total energy demand (TED) was calculated by linear extrapolation and $\mathrm{VO}_{2} \mathrm{Ac}$ was the integration of $\mathrm{VO}_{2}$ during the all-out test over the time, as given by Equation (1).

$\mathrm{VO}_{2} \mathrm{Ac}=\int_{t 1}^{t 2} V O_{2} \cdot d t$

The imprecision of the AOD (AOD ${ }^{\text {error }}$ ) was calculated as follows [26]:

$\mathrm{AOD}^{\text {error }}=\sqrt{(\text { error for total }} \mathrm{ED}^{2}+$ error for $\left.\mathrm{VO}_{2} \mathrm{Ac}^{2}\right)$

where

error for total ED = error for ED . duration

and

error for $\mathrm{VO}_{2} \mathrm{Ac}=$ error for $\mathrm{VO}_{2}$. duration

The error for ED is given by the standard error of the predicted value for the energy demand. The error for $\mathrm{VO}_{2}$ was assumed to be $3 \%$ [27].

\section{Statistical analysis}

Data was analysed with SPSS 14.0. (SPSS Science, Chicago, USA). Normality assumption was verified with the Shapiro-Wilk test

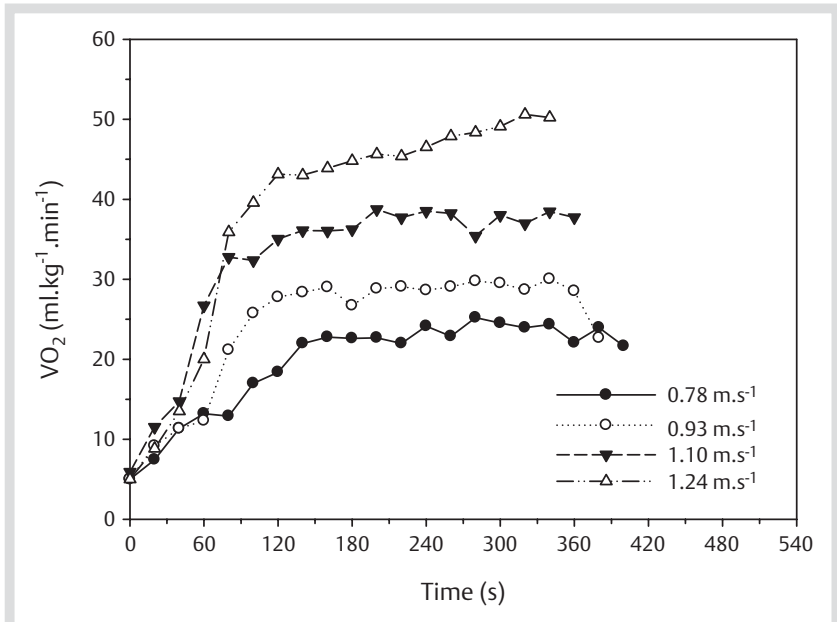

Fig. $1 \mathrm{VO}_{2}$ on-kinetics pattern for one subject in the four sub maximal bouts.

for all variables. The results are presented as means \pm one standard deviation (SD). Linear regression was used on all appropriate data. The scatter around the regression line $(S y \cdot x)$ was used to assess the robustness of the regression lines. The standard error of the predicted value (SEP) was used to assess the robustness of the linear extrapolation of the energy cost of swimming. Differences between groups of subjects were assessed with one way ANOVA and Scheffe post-hoc, after normality assumption was verified. Simple bivariate correlations between variables were investigated with the Pearson product-moment coefficient, taking values from the overall sample. The statistical significance was set to $\mathrm{p} \leq 0.05$.

\section{Results}

$\nabla$

All subjects completed four sub maximal bouts with a duration comprised between $5 \mathrm{~min}$ and $6 \mathrm{~min} 30 \mathrm{~s}$, where $\mathrm{VO}_{2}$ achieved a steady-state. The first three bouts were performed at an intensity below the $4 \mathrm{mmol} \cdot \mathrm{L}^{-1}$ lactate threshold and the fourth bout above this threshold. $\odot$ Fig. 1 shows a typical $\mathrm{VO}_{2}$ on-kinetics pattern for one subject in the four sub maximal bouts and $\odot$ Fig. 2 depicts the regression lines from steady-state $\mathrm{VO}_{2}$ and swimming velocity in the three groups of subjects. Some subjects were engaged in a fifth bout to attain voluntary exhaustion, but all these failed to conclude the full bout. Mean $( \pm S D)$ values for blood lactate and relative intensity expressed as peak $\mathrm{VO}_{2}$ percentage were, respectively, in the four sub maximal bouts: $2.26 \pm 0.87 \mathrm{mmol} \cdot \mathrm{L}^{-1}$ and $53.54 \pm 9.30 \% ; 2.32 \pm 0.92 \mathrm{mmol} \cdot \mathrm{L}^{-1}$ and $60.29 \pm 7.43 \% ; 2.85 \pm 1.24 \mathrm{mmol} \cdot \mathrm{L}^{-1}$ and $75.68 \pm 8.47 \%$; $5.63 \pm 3.06 \mathrm{mmol} \cdot \mathrm{L}^{-1}$ and $88.75 \pm 10.24 \%$.

Peak $\mathrm{VO}_{2}$ was $59.46 \pm 7.00 \mathrm{ml} \cdot \mathrm{kg}^{-1} \cdot \mathrm{min}^{-1}$ in the overall sample, with different mean values $[\mathrm{F}(2 ; 6.172)=930.627 ; \mathrm{p}=0.006]$ between the $200 \mathrm{~m}$ swimmers' group $\left(63.79 \pm 5.44 \mathrm{ml} \cdot \mathrm{kg}^{-1} \cdot \mathrm{min}^{-1}\right)$ and the $100 \mathrm{~m}$ group $\left(55.82 \pm 7.35 \mathrm{ml} \cdot \mathrm{kg}^{-1} \cdot \mathrm{min}^{-1}\right)$. In the $400 \mathrm{~m}$ group peak $\mathrm{VO}_{2}$ was $56.23 \pm 2.95 \mathrm{ml} \cdot \mathrm{kg}^{-1} \cdot \mathrm{min}^{-1}$. Energy cost of swimming was $0.583 \pm 0.06 \mathrm{ml} \cdot \mathrm{kg}^{-1} \cdot \mathrm{m}^{-1}, 0.675 \pm 0.06 \mathrm{ml} \cdot \mathrm{kg}^{-1}$. $\mathrm{m}^{-1}$ and $0.574 \pm 0.04 \mathrm{ml} \cdot \mathrm{kg}^{-1} \cdot \mathrm{m}^{-1}$, respectively, in the $100 \mathrm{~m}$, $200 \mathrm{~m}$ and $400 \mathrm{~m}$ groups (non-significant differences).

- Table 1 presents measurements and calculations in the three all-out bouts that were performed. 


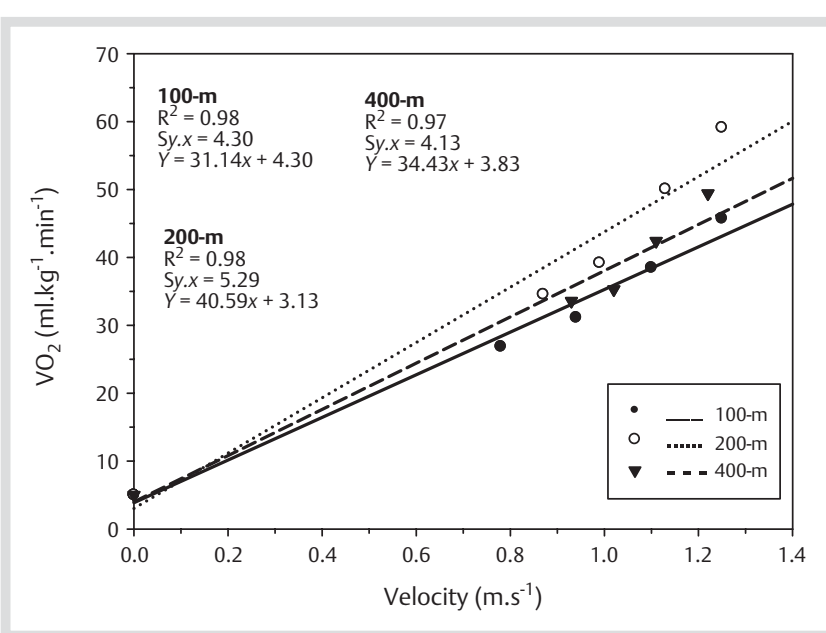

Fig. 2 Regression lines $\left(\mathrm{VO}_{2}\right.$ as function of swimming velocity) in the three groups of subjects (mean values recorded for each group in the graded test. $\mathrm{N}=11$ for $100-\mathrm{m} ; \mathrm{n}=13$ for $200-\mathrm{m}$; $\mathrm{n}=5$ for $400-\mathrm{m}$.

Table 1 Measurements and calculations in the three all-out bouts (means \pm SD).

\begin{tabular}{|c|c|c|c|}
\hline & $100 m(n=11)$ & $200 m(n=13)$ & $400 m(n=5)$ \\
\hline $\operatorname{VEL}\left(\mathrm{m} \cdot \mathrm{s}^{-1}\right)$ & $1.53 \pm 0.09$ & $1.41 \pm 0.12 \#$ & $1.30 \pm 0.04$ * \\
\hline ANAER (\%) & $30.88 \pm 10.49$ & $13.04 \pm 8.44^{*}$ & $4.83 \pm 6.05 *$ \\
\hline $\mathrm{AOD}\left(\mathrm{ml} \cdot \mathrm{kg}^{-1}\right)$ & $20.55 \pm 7.41$ & $17.53 \pm 13.53$ & $11.91 \pm 14.72$ \\
\hline $\begin{array}{l}\text { SEP } \\
\left(\mathrm{ml} \cdot \mathrm{kg}^{-1} \mathrm{~min}^{-1}\right)\end{array}$ & $3.12 \pm 2.67$ & $3.81 \pm 1.86$ & $2.04 \pm 0.86$ \\
\hline $\begin{array}{l}\mathrm{C} 195 \% \\
\left(\mathrm{ml} \cdot \mathrm{kg}^{-1} \mathrm{~min}^{-1}\right)\end{array}$ & $16.61 \pm 11.75$ & $21.32 \pm 12.83$ & $12.57 \pm 5.91$ \\
\hline $\begin{array}{l}\text { AOD error } \\
\left(\mathrm{ml} \cdot \mathrm{kg}^{-1}\right)\end{array}$ & $3.04 \pm 1.29$ & $9.43 \pm 3.58$ * & $13.37 \pm 4.33^{*}$ \\
\hline $\begin{array}{l}\text { Peak BL } \\
\left(\mathrm{mmol} \cdot \mathrm{L}^{-1}\right)\end{array}$ & $12.88 \pm 3.03$ & $10.01 \pm 2.86$ & $7.78 \pm 2.98$ \\
\hline \multicolumn{4}{|c|}{$\begin{array}{l}\text { VEL= average swimming velocity; ANAER = anaerobic fraction of energy release; } \\
\text { AOD = accumulated oxygen deficit; } \mathrm{SEP}=\text { standard error of the predicted energy } \\
\text { cost; CI95\%=95\% confidence interval of the predicted energy cost; } \\
\text { AODerror = estimation error of AOD; Peak BL= peak blood lactate post-exercise } \\
\text { * = Different from } 100-\mathrm{m}(\mathrm{p}<0.01) ; \#=\text { different from } 100-\mathrm{m}(\mathrm{p}<0.05)\end{array}$} \\
\hline
\end{tabular}

Swimming velocity correlated with Peak BL $(r=0.68, \mathrm{p}<0.01)$ and with ANAER $(r=0.49, p<0.01)$. Peak BL correlated also with ANAER $(r=0.69, p<0.01)$. Additionally, ANAER was inversely correlated with Peak $\mathrm{VO}_{2}(\mathrm{r}=-0.45, \mathrm{p}<0.05)$ and with AOD ${ }^{\text {error }}$ $(r=-0.71, p<0.01)$. The AOD correlated only with energy cost of swimming $(\mathrm{r}=0.45, \mathrm{p}<0.05)$.

\section{Discussion}

$\checkmark$

The present study intended to investigate the AOD method in front crawl swimming. The main findings of the present study were that the robustness of oxygen uptake/swimming velocity regression lines was acceptable (with standard errors of $\approx 4-5 \mathrm{ml} \cdot \mathrm{kg}^{-1} \cdot \mathrm{min}^{-1}$ ) The AOD absolute errors were small but relative to the AOD values that were estimated they can be viewed as high (especially in the $400 \mathrm{~m}$ bout).

The use of the $\mathrm{VO}_{2}$ /exercise intensity regression to estimate the Cs is present in the literature $[3,14,21]$, although providing little information about the $\mathrm{VO}_{2}$ on-kinetics of the subjects that were assessed. Nevertheless, others have conducted pilot studies on the $\mathrm{VO}_{2}$ kinetics during front crawl swimming $[17,28]$. More- over, the time to attain $\mathrm{VO}_{2}$ steady-state has been shown to be lower in subjects with high aerobic ability [10]. The main assumption to use the $\mathrm{VO}_{2}$ /exercise intensity regression line to estimate the $\mathrm{Cs}$ is the establishment of steady-state sub maximal $\mathrm{VO}_{2}$ at several exercise intensities. Thus, the sub maximal exercise bouts must have a duration that enables the $\mathrm{VO}_{2}$ to attain a steady state. In the present study, all subjects completed four full sub maximal bouts with a duration comprised between $5 \mathrm{~min}$ and $6 \mathrm{~min} 30 \mathrm{~s}$, where $\mathrm{VO}_{2}$ achieved a steady-state (see $\odot$ Fig. 1). In the first two bouts $\mathrm{VO}_{2}$ attained a steady-state within the first $3 \mathrm{~min}$ of exercise, while in the third bout it took approximately 3 min 30 s to attain such status. These three bouts were performed at an intensity below $75 \%$ of subjects' peak $\mathrm{VO}_{2}$ and with a blood lactate less than $3 \mathrm{mmol} \cdot \mathrm{L}^{-1}$. In the fourth bout, which was performed at a relative intensity of $88.75 \pm 10.24 \%$ peak $\mathrm{VO}_{2}$ $\left(5.63 \pm 3.06 \mathrm{mmol} \cdot \mathrm{L}^{-1}\right.$ for $\left.\mathrm{BL}\right)$, the $\mathrm{VO}_{2}$ on-kinetics presented a different pattern. It was possible to observe in most of the subjects an apparent $\mathrm{VO}_{2}$ steady-state (given by a variation less than $2 \mathrm{ml} \cdot \mathrm{kg}^{-1} \cdot \mathrm{min}^{-1}$ ) in the last min of exercise. However, the fact that $\mathrm{VO}_{2}$ mean values over the last minute of exercise were more than $300 \mathrm{ml} \cdot \mathrm{min}^{-1}$ higher than the value recorded at the $3^{\text {rd }} \mathrm{min}$, it is possible that a true slow component was present [23] and that $\mathrm{VO}_{2}$ could still have risen more if the exercise bout had been prolonged. Others have also found similar $\mathrm{VO}_{2}$ slow component mean values in competitive swimmers $[8,12]$.

The regression lines obtained from mean $\mathrm{VO}_{2}$ and swimming velocity during the sub maximal bouts in the graded test (see 0 Fig. 2) revealed a higher slope for the $200 \mathrm{~m}$ group and a lower slope in the $100 \mathrm{~m}$ group. Consequently, the mean Cs varied (non-significantly) from $0.574 \pm 0.04 \mathrm{ml} \cdot \mathrm{kg}^{-1} \cdot \mathrm{m}^{-1}(100 \mathrm{~m}$ group) to $0.675 \pm 0.06 \mathrm{ml} \cdot \mathrm{kg}^{-1} \cdot \mathrm{m}^{-1}(200 \mathrm{~m})$, with an intermediate mean value in the $400 \mathrm{~m}$ group $\left(0.583 \pm 0.06 \mathrm{ml} \cdot \mathrm{kg}^{-1} \cdot \mathrm{m}^{-1}\right)$. Since the peak $\mathrm{VO}_{2}$ of the subjects included in the $200 \mathrm{~m}$ group was higher when compared with the remaining subjects , these differences may partly explain the higher Cs observed in the $200 \mathrm{~m}$ group. These mean values are consistent with the observations by Reis et al. [24] and that by Barbosa et al. [4] on similar subject cohort.

The linearity of the scatter was high in the three groups of subjects and the standard error of estimate varied little $\left(\approx 4-5 \mathrm{ml} \cdot \mathrm{kg}^{-1} \cdot \mathrm{min}^{-1}\right)$. We could not find in the literature studies with a similar subject cohort that provided information on this type of regression robustness during front crawl swimming. Our criticism regarding the lack of data on the sub maximal $\mathrm{VO}_{2}$ on-kinetics in the literature is also applicable here. The use of mathematical models to explain physiological responses warrants a clear identification of the precision of those models. In the present case, energy cost is estimated and not measured, therefore requiring proper presentation of its robustness. The error of our regressions was $\approx 4-5 \mathrm{ml} \cdot \mathrm{kg}^{-1} \cdot \mathrm{min}^{-1}$, which is above our previous observations in running $[25,26]$.

When the individual regression lines were used to extrapolate the energy demand in the all-out bouts, we found no differences between the three swimming distances and the standard errors of prediction were $\approx 3-4 \mathrm{ml} \cdot \mathrm{kg}^{-1} \cdot \mathrm{min}^{-1}$. In our opinion this precision can be considered acceptable, since the mean energy demand for the all-out bouts was $58.03 \pm 8.66 \mathrm{ml} \cdot \mathrm{kg}^{-1} \cdot \mathrm{m}^{-1}$, which gives us a relative error of prediction of $\approx 6 \%$. However, in running and cycling exercise, others have reported lower errors of the predicted value $[25,30]$.

It has also been suggested that the combined use of both sub and supra $4 \mathrm{mmol} \cdot \mathrm{L}^{-1}$ lactate threshold exercise intensities may 
affect the model precision and or validity [5]. An absence of such phenomenon with endurance-trained runners during treadmill exercise has been described [25]. The alleged sensitivity of the model to exercise intensity could be explained by the fact that including high exercise intensities (above the anaerobic threshold) creates more deviations from linearity. Since we observed the appearance of a $\mathrm{VO}_{2}$ slow component in the last bout of the grade test and a less evident $\mathrm{VO}_{2}$ steady-state, we re-calculated our regression with exclusion of data from that last bout. We found that the linearity of the model did not change and that standard error of the regression as well as the standard error of the predicted value increased slightly $(\approx 5 \%$ and $\approx 3 \%$ increases, respectively). However the $95 \%$ confidence intervals of the predicted value increased four-fold, which clearly lowers the robustness of the model when it comes to extrapolation beyond the exercise intensities included in the graded test. Consequently, also the error in AOD estimation would tend to increase with this procedure (especially in the $100 \mathrm{~m}$ distance with a two-fold increase). These results indicate that the inclusion of higher intensities in the regression line is necessary to improve the precision of the model when extrapolations are to be made into supra maximal exercise intensities.

It has been suggested that an underestimation in the energy cost could be a result of an underestimation of the steady-state $\mathrm{VO}_{2}$ at high sub maximal exercise intensities, due to the interference of the $\mathrm{O}_{2}$ slow component [5]. However, in the present study, the slope of the regression lines without the $4^{\text {th }}$ bout of exercise lowered the energy cost of swimming by $\approx 7 \%$. If an underestimation of the true energy cost during the $4^{\text {th }}$ bout due to a possible underestimation in steady-state $\mathrm{VO}_{2}$ was present in our subjects, the opposite tendency was to be expected. Therefore, we decided to maintain all sub maximal $\mathrm{VO}_{2}$ measurements in the regression lines.

The accumulated oxygen deficit (AOD) has been vastly used to quantify anaerobic energy release during exercise in different physical activities, especially in running $[6,9,26]$ but is rarely used in swimming [21]. In the present study we found AOD mean values of $20.55 \pm 7.41 \mathrm{ml} \cdot \mathrm{kg}^{-1}, 17.53 \pm 13.53 \mathrm{ml} \cdot \mathrm{kg}^{-1}$ and $11.91 \pm 14.72 \mathrm{ml} \cdot \mathrm{kg}^{-1}$, respectively, in the $100 \mathrm{~m}, 200 \mathrm{~m}$ and $400 \mathrm{~m}$ all-out bouts. These values are much lower than those by Ogita et al. [21] for supra maximal 2-3 min bouts in the swimming flume.

The anaerobic fractions of energy release (ANAER) in the present study were $\approx 31 \%$ in the $100 \mathrm{~m}$ bout, $\approx 13 \%$ in the $200 \mathrm{~m}$ bout and $\approx 5 \%$ in the $400 \mathrm{~m}$ bout. Despite the few studies on the AOD during pool swimming [32], other approaches have been used to quantify ANAER in real or simulated competitions performed by swimmers. Estimations from post-exercise BL, together with assumptions for alactic energy as well as for aerobic energy release, have indicated higher values than those in the present study for the same distance events: $14-18 \%$ in $400 \mathrm{~m}[15,34]$; $29 \%$ in $200 \mathrm{~m}$ [34] and $51 \%$ in $100 \mathrm{~m}$ [34]. Since the subjects in the study by Zamparo et al. [34] were younger than those in the present study and were tested in the early preparation phase of the season, while our subjects were tested after a competitive season, it is not likely that differences in the development of anaerobic ability explain the smaller ANAER in the present study. Thus, differences in the method that was used to calculate ANAER are more likely to explain the discrepancies. Calculating the ANAER from AOD assessment, Troup [32,33] also found higher estimations for pool swimming (55\% in $100 \mathrm{~m}$ and $35 \%$ in $200 \mathrm{~m}$ ) and for flume swimming (55\% in $100 \mathrm{~m}$ and $39 \%$ in
$200 \mathrm{~m}$ ). The higher competitive level of the subjects that were tested by Troup [32,33] may help to explain the larger ANAER. The post-exercise peak BL in the present study presented a small variation between the three all-out exercise bouts (see - Table 1). Our mean values are lower than those reported in the literature for trained swimmers performing the same distances, especially in the 200 - and $400 \mathrm{~m}$ events $[15,16]$. This may be explained by the different athletic ability of the subjects. We tested young national-level competitive swimmers while those reports in the literature have assessed high-performance subjects. Another factor that may have contributed to the discrepancies is the fact that the swimmers in the present study used a valve attached to a gas analyzer. The apparatus clearly lowers the average swimming speed of the subjects during the bouts, as compared to free-swimming, and this may result in a lower anaerobic energy demand. Since AOD and lactate both reflect the anaerobic pathway, it is possible that in those studies with high performance subjects swimming in a free condition, larger true values of AOD were present. Indeed, in the present study both peak BL and ANAER correlated positively with swimming velocity during the all-out test $(r=0.68, p<0.01$ and $r=0.49$, $\mathrm{p}<0.01$, respectively). On the other hand, peak BL and ANAER were also correlated $(r=0.69, p<0.01)$. Surprisingly, the AOD did not correlate with peak BL. These results suggest that although AOD and peak BL may both reflect anaerobic pathways of energy release, they do not necessarily represent the same time-course response of human physiology during high-intensity exercise. The fact that AOD is calculated based on measurements during exercise and $\mathrm{BL}$ is measured post-exercise may contribute to a possible mismatch between these two. During supra maximal running it has been demonstrated that AOD attains a maximal value between $2-3 \mathrm{~min}$ of treadmill exhaustive exercise [19]. Our data seem to indicate that front crawl swimming is much different, since a significantly lower AOD was observed in the $200 \mathrm{~m}$ and $400 \mathrm{~m}$ distances, when compared with the $100 \mathrm{~m}$ distance (see $\odot$ Table 1). The largest AOD mean value observed in the short-distance $\left(20.55 \pm 7.41 \mathrm{ml} \cdot \mathrm{kg}^{-1}\right)$ is probably not the subjects maximal AOD. In the future it may be interesting to assess the swimmers' response during a $50 \mathrm{~m}$ all out bout to confirm if AOD is larger than our observations in the $100 \mathrm{~m}$. Anyway, in our opinion the nature of swimming itself (liquid environment and low frequency of movement, as compared with all-out running) may prevent maximal AOD appearing during this type of activity. Therefore, an assessment of swimmers AOD during high-intensity running or cycling may also be an interesting issue. The AOD variability was high, especially in the $400 \mathrm{~m}$ bout. The larger variability observed in the longer distance reflects a time-effect. Since the AOD is an amount of energy and not a rate of energy production, it is natural that the longer the exercise bout lasts the larger are the chances that inter-individual differences in AOD are increased.

Due to the uneven amount of subjects in the three groups as well as the smaller size of the $400 \mathrm{~m}$ group, our results may present some bias. In the case of the $400 \mathrm{~m}$ ANAER estimations, another issue helps to explain the large variability. Due to a mean swimming velocity that, for some subjects, is below their peak $\mathrm{VO}_{2}$ velocity, these subjects are able to swim the $400 \mathrm{~m}$ distance without presenting AOD. This phenomenon illustrates the dependency of AOD (thus ANAER as calculated in the present study) on the $\mathrm{VO}_{2}$ kinetics during exercise. Indeed, due to the longer duration of the $400 \mathrm{~m}$ bout, chances are that the swimmers attain peak $\mathrm{VO}_{2}$ (or near-to-peak $\mathrm{VO}_{2}$ ) values, thereby 
increasing the mean $\mathrm{VO}_{2}$ during the bout to a value above the predicted energy requirements. On the other hand, the mechanical constraints imposed by the Aquatrainer, also tend to lower the average velocity during the bout, thereby lowering the predicted energy demand. In fact, we found that AOD was negative in some subjects, where the mean $\mathrm{VO}_{2}$ during the bout was above the predicted energy requirement. Therefore, the data obtained from the $400 \mathrm{~m}$ event should be interpreted with caution and serve merely as an example of a possible limitation to assess AOD over this distance.

In the present study, the error of AOD estimation was significantly larger (see $\bullet$ Table 1$)$ in the $200 \mathrm{~m}\left(9.43 \pm 3.58 \mathrm{ml} \cdot \mathrm{kg}^{-1}\right.$ ) and in the $400 \mathrm{~m}\left(13.37 \pm 4.33 \mathrm{ml} \cdot \mathrm{kg}^{-1}\right)$ bouts, when compared with that calculated for the $100 \mathrm{~m}$ bout $\left(3.04 \pm 1.29 \mathrm{ml} \cdot \mathrm{kg}^{-1}\right)$. Moreover, considering the AOD values that were assessed in the three distances, the relative error is much smaller for the $100 \mathrm{~m}$ event. Relative to the AOD values that were estimated these errors can be viewed as high (especially in the $400 \mathrm{~m}$ bout). In the literature, we have not found a single reference to the AOD error in swimming. Therefore, we were only able to refer to previous references regarding other types of exercise (i.e. running), which are typically $\approx 4-5 \mathrm{ml} \cdot \mathrm{kg}^{-1}[19,25]$.

In conclusion, the oxygen uptake/swimming velocity regression lines allowed an extrapolation of the Cs to higher intensities with a high precision (standard errors of prediction of $\approx 3-4 \mathrm{ml}$. $\left.\mathrm{kg}^{-1} \cdot \mathrm{min}^{-1}\right)$. The absolute AOD error in the all-out bouts increased concomitantly with the distance and, since the absolute AOD values followed an inverse tendency, the relative error for AOD estimation was much lower in the $100 \mathrm{~m}$ event.

Affiliations

Department of Sport Sciences, Exercise and Health, University of Trás-os-Montes and Alto Douro, Vila Real, Portugal

Research Centre in Sport, Health and Human Development, Vila Real,

Portugal

Department of Sport Sciences, University of Beira Interior, Covilhã, Portugal IUSM, University of Rome, Rome, Italy

\section{References}

1 Baldari C, Bonavolontà V, Emerenziani GP, Gallotta MC, Silva AJ, Guidetti L. Accuracy, reliability, linearity of Accutrend and Lactate Pro versus EBIO plus analyzer. Eur J Appl Physiol 2009; 107: 105-111

2 Barbosa TM, Bragada JA, Reis VM, Marinho DA, Carvalho C, Silva AJ. Energetics and biomechanics as determining factors of swimming performance: Updating the state of the art. J Sci Med Sport 2009; 29, [Epub ahead of print]

3 Barbosa TM, Fernandes $R$, Keskinen $K L$, Colaço P, Cardoso C, Silva J, Vilas-Boas JP. Evaluation of the energy expenditure in competitive swimming strokes. Int J Sports Med 2006; 27: 894-899

4 Barbosa TM, Fernandes R, Keskinen KL, Vilas-Boas JP. The influence of stroke mechanics into energy cost of elite swimmers. Eur J Appl Physiol 2008; 103: 139-149

5 Bearden $S$, Moffat $R$. Leg electromyography and the $\mathrm{VO}_{2}$-power relationship during bicycle ergometry. Med Sci Sport Exerc 2001; 33: $1241-1245$

6 Bickham D, Le Rossignol P, Gibbons C, Russell AP. Re-assessing accumulated oxygen deficit in middle-distance runners. J Sci Med Sport 2001; 5: 336-340

7 Costill D, Kovaleski J, Porter D, Kirwan J, Fielding R, King D. Energy expenditure during front crawl swimming: predicting success in middle-distance events. Int J Sports Med 1985; 6: 266-270

8 Demarie S, Sardella F, Billat V, Magini $W$, Faina $M$. The $\mathrm{VO}_{2}$ slow component in swimming. Eur J Appl Physiol 2001; 84: 95-99

9 Duffield R, Dawson B, Goodman C. Energy system contribution to 100$\mathrm{m}$ and 200-m track running events. J Sci Med Sport 2004; 7: 302-313

10 Edwards A, Chalis $N$, Chapman J, Claxton D, Fysh $M . \mathrm{VO}_{2}$ kinetics determined by PRBS Techniques differentiate elite endurance runners from elite sprinters. Int J Sports Med 1999; 20: 1-6
11 Faulkner JA. New perspectives in training for maximum performance. J Am Med Assoc 1968; 205: 741-746

12 Fernandes RJ, Keskinen KL, Colaço P, Querido AJ, Machado LJ, Morais PA Novais DQ, Marinho DA, Vilas-Boas JP. Time limit at $\mathrm{VO}_{2 \max }$ velocity in elite crawl swimmers. Int J Sports Med 2008; 29: 145-150

13 Harriss DJ, Atkinson G. International Journal of Sports Medicine - Ethical Standards in Sport and Exercise Science Research. Int J Sports Med 2009; 30: 701-702

14 Kjendlie PL, Ingjer F, Madsen Ø, Stallman RK, Stray-Gundersen J. Differences in the energy cost between children and adults during front crawl swimming. Eur J Appl Physiol 2004; 91: 473-480

15 Laffite LP, Vilas-Boas JP, Demarle A, Silva J, Billat V. Changes in physiological and stroke parameters during a maximal 400-m free swimming test in elite swimmers. Can J Appl Physiol 2004; 29: S17-S31

16 Lindh AM, Peyrebrune MC, Ingham SA, Bailey DM, Folland JP. Sodium bicarbonate improves swimming performance. Int J Sports Med 2008; 29: 519-523

17 Machado L, Querido A, Keskinen KL, Fernandes R, Vilas-Boas JP. Mathematical modeling of the slow component of oxygen uptake kinetics in front crawl. In: Vilas-Boas JP, Alves F, Marques A (eds). Book of Abstracts of the Xth Biomechanics and Medicine in Swimming. Port J Sport Sci 2006; 6 (Supl. 1): 144-146

18 Margaria $R$, Cerretelli $P$, di Prampero $P$, Massari $C$, Torelli $G$. Kinetics and mechanics of oxygen debt contraction in man. J Appl Physiol 1963; 18: 277-371

19 Medbø J, Mohn A, Tabata I, Bahr R, Vaage O, Sejersted O. Anaerobic capacity determined by maximal accumulated $\mathrm{O} 2$ deficit. J Appl Physiol 2008; 64: 50-60

20 Medbø JI, Toska K. Lactate release, concentration in blood, and apparent distribution volume after bicycling exercise. Jap J Physiol 2001; 51: 303-312

21 Ogita F, Onodera T, Tabata I. Effect of hand paddles on anaerobic energy release during supramaximal swimming. Med Sci Sports Exerc 1999; 31: 729-735

22 Ogita F, Tabata I. Aerobic and anaerobic energy release during supramaximal swimming at different levels of hypobaric hypoxia. Med Sci Sports Exerc 2000; 32: S336

23 Reis VM, Guidetti L, Duarte JA, Ascensão A, Silva AJ, Sampaio JE, Russell $A P$, Baldari $C$. Slow component of $\mathrm{VO}_{2}$ during level and uphill treadmill running: relationship to aerobic fitness in endurance runners. J Sports Med Phys Fitness 2007; 47: 135-140

24 Reis V, Silva AJ, Reis A, Garrido N, Moreira A, Carneiro A, Marinho D, Neto $S$. Assessment of sub maximal and supra maximal swimming energy cost in crawl and breaststroke swimmers. In: Vilas-Boas JP, Alves F, Marques A (eds). Book of Abstracts of the Xth Biomechanics and Medicine in Swimming. Port J Sport Sci 2006; 6 (Supl. 1): 55-56

25 Reis VM, Silva AJ, Ascensão A, Duarte JA. Inclusion of exercise intensities above the lactate threshold in $02 /$ running speed regression does not improve the precision of accumulated oxygen deficit estimation in endurance-trained runners. J Sports Sci Med 2005; 4: 455-462

26 Reis VM, Duarte JA, Espírito-Santo J, Russell AP. Determination of accumulated oxygen deficit during a 400 m run. J Exerc Physiol 2004; 7: 77-83

27 Robergs RA, Burnett AF. Methods used to process data from indirect calorimetry and their application to $\mathrm{VO}_{2} \max$. J Exerc Physiol 2003; 6: 44-57

28 Rodríguez F, Keskinen K, Keskinen O, Malvela M. Oxygen uptake kinetics during free swimming: a pilot study. In: Chatard JC. (ed). Biomechanics and Medicine in Swimming IX; 2002. University Press, Saint-Étienne, 379-390

29 Russell AP, Rossignol P, Snow R, Lo S. Cycling at 120 when compared to $80 \mathrm{rev} / \mathrm{min}$ increases the accumulated oxygen deficit but does not affect the precision of its calculation. J Exerc Physiol 2002; 5: 32-38

30 Russell AP, Rossignol P, Lo S. The precision of estimating the total energy demand: implications for the determination of the accumulated oxygen deficit. J Exerc Physiol 2000; 3: 55-63

31 Silva A, Reis VM, Reis A, Garrido N, Moreira A, Carneiro A, Alves F. Associations between energy release and performance in a supramaximal effort of $200 \mathrm{~m}$ in crawl. In: Vilas-Boas JP, Alves F, Marques A (eds). Book of Abstracts of the Xth Biomechanics and Medicine in Swimming. Port J Sport Sci 2006; 6 (Supl. 1): 59-60

32 Troup J. Aerobic characteristics of the four competitive strokes. In: Troup J (ed). International Center for Aquatic Research Annual. Studies by the International Center for Aquatic Research (1990-1991). Colorado Springs, US Swimming Press; $1991^{\mathrm{a}} ; 3-7$ 
33 Troup J. Measurement of swimming anaerobic capacity. In: Troup J (ed). International Center for Aquatic Research Annual. Studies by the International Center for Aquatic Research (1990-1991). Colorado Springs, US Swimming Press; $1991^{\text {b }}$; 9-16

34 Zamparo P, Capelli C, Cautero M, Di Nino A. Energy cost of front crawl swimming at supra-maximal speeds and underwater torque in young swimmers. Eur J Appl Physiol 2000; 83: 487-491
35 Zoeller, Nagle E, Robertson R, Moyna N, MLephart S, Goss F. Peak blood lactate and accumulated oxygen deficit as indicies of freestyle swimming performance in trained adult female swimmers. Journal of Swimming Research 2000; 14: 18-25 